\title{
Effect of Thuja occidentalis and Levamisole on Sperm Motion Characteristics and Morphology in FMD Vaccinated Holstein $\times$ Sahiwal Bulls
}

\author{
Ajayvir Singh Sirohi ${ }^{1 *}$, Shrikant Tyagi ${ }^{1}$, Naimi Chand ${ }^{1}$, Sushil Kumar ${ }^{2}$, Ankur Sharma ${ }^{1}$, \\ Rachna Tyagi ${ }^{1}$, Sarmesh Arya ${ }^{1}$ and Sarika ${ }^{1}$ \\ ${ }^{1}$ Division of Cattle Physiology and Reproduction, ICAR-CIRC, Meerut Cantt, INDIA \\ ${ }^{2}$ Division of Cattle Genetics and Breeding, ICAR-CIRC, Meerut Cantt, INDIA \\ *Corresponding author: AS Sirohi; E-mail: ajaysirohi35@gmail.com
}

Received: 17 Sept., 2020

Revised: 13 Oct., 2020

Accepted: 16 Oct., 2020

\begin{abstract}
To assess the effect of Thuja (Thuja occidentalis) and Levamisole on the spermiogram of FMD vaccinated crossbred bulls, 24 adult Frieswal (Holstein $\times$ Sahiwal) bulls were divided into four groups viz. GC (control; no vaccination), GV (vaccinated), GL (vaccinated + Levamisole) and GH (vaccinated + Thuja). The bulls of GV, GL and GH groups were vaccinated with FMD vaccine. Four injections of levamisole were administered to the bulls of GL group at weekly interval starting from one week prior to the FMD vaccination. Homoeopathy medicine (Thuja) was given orally to the bulls of GH group consecutively on four days (on 4, 3, 2 \& 1 day, respectively) before FMD vaccination. Average rectal temperature in vaccinated bulls increased significantly than in non-vaccinated bulls after $24 \mathrm{hrs}$ of FMD vaccination. In GH, it was similar to GC in $36 \mathrm{~h}$, however, became normal in all groups in $48 \mathrm{~h}$ of vaccination. Average VAP and VSL values were higher $(\mathrm{p}<0.05)$ in GC than in the other groups. Bulls of GH had higher $(\mathrm{p}<0.05)$ initial sperm subjective and CASA progressive motility and linearity than in GV. After six weeks VSL values continued to be significantly higher in GC than in GL but it was similar in GV and GH. Total sperm abnormalities were within the prescribed limit of semen preservation up to first week after vaccination in all the groups. The results of the present study indicated that Thuja was able to prevent deterioration in sperm kinetic parameters subsequent to FMD vaccination in crossbred bulls.
\end{abstract}

\section{HIGHLIGHTS}

( Assessment of administration of Thuja and Levamisole in FMD vaccinated crossbred breeding bulls.

(0 To study the effect on semen quality.

(0 Thuja was able to prevent deterioration in sperm kinetic parameters.

Keywords: Crossbred bull, Levamisole, Semen quality, Thuja

The outbreaks of highly contagious Foot and Mouth disease (FMD) of cloven footed animals occur all over the country every year. Likewise, its vaccination in other livestock, the breeding bulls at semen stations are also vaccinated to prevent its occurrence. The poor semen quality after FMD vaccination in Frieswal bulls has been reported by Sirohi et al. (2016). The available reports indicate poor semen quality due to FMD vaccination in different breeds of cattle (Mathur et al., 2003). Perumal et al. (2013) reported increased incidence of sperm abnormalities following vaccination. The vaccination in breeding bulls affected semen quality due to vaccine stress and anaphylactic shock (Murugavel et al., 1997). Consequent upon vaccination, the severity of damage depends on the extent and duration of the thermal stress (Waites and Setchell, 1990).

The studies have been conducted to enhance immune

How to cite this article: Sirohi, A.S., Tyagi, S., Chand, N., Kumar, S., Sharma, A., Tyagi, R., Arya, S. and Sarika. (2020). Effect of Thuja occidentalis and Levamisole on sperm motion characteristics and morphology in FMD vaccinated holstein $\times$ Sahiwal bulls. J. Anim. Res., 10(5): 799-802.

Source of Support: None; Conflict of Interest: None 
response and/or to mitigate vaccination stress with the use of immune-modulators. The immuno-pharmacological potential of widely used Thuja occidentalis in homeopathy and evidence-based phytotherapy has been demonstrated in numerous in vitro and in vivo test models showing its immune-stimulating and antiviral activities (Naser et al., 2005). Besides, non-specific immune-modulator like levamisole has also been used to potentiate immune responses in livestock animals. Although levamisole was used as an immunoprotector or immunopotentiator (Montenegro et al., 1992) other authors also question the action of levamisole as an immunomodulator (Abath et al., 1988). Duarte et al. (2019) reported that the cows treated with levamisole during pre-partum period showed no improvement with respect to immune-potentiator in postpartum performance and it needs further reassessment.

It is very much obvious from the findings of studies conducted that there is a need to intervene to reduce stress due to FMD vaccination and subsequently to obtain quality semen from the crossbred bulls. Therefore, present experiment was conducted to analyze the effects of Levamisole and Thuja on semen quality parameters after FMD vaccination in Frieswal bulls (Holstein Friesian $\times$ Sahiwal).

\section{MATERIALS AND METHODS}

\section{Experimental animals and treatments}

The present study was carried out at Semen Freezing Laboratory, ICAR-Central Institute for Research on cattle, Meerut Cantt. Adult Frieswal (Holstein Friesian $\times$ Sahiwal) breeding bulls (24) selected randomly from the Bull Rearing Unit were divided into four groups GC, GV, GL and GH. These bulls were kept in individual pens under loose housing system and were managed with uniform management practices. The bulls of GC (control) were not vaccinated for FMD and were given no treatment. However, bulls of GV, GL and GH groups were vaccinated with FMD vaccine @ $2.0 \mathrm{ml}$ by deep I/M route, which contained FMDV strains O, A and Asia 1. Four injections of levamisole $\mathrm{HCl} @ 2.5 \mathrm{mg} / \mathrm{kg}$ body weight were administered through subcutaneous route to the each bull of GL group at weekly interval starting from one week prior to the FMD vaccination. Homoeopathy medicine was prepared by mixing $2 \mathrm{ml}$ medicine into 10 $\mathrm{ml}$ of distilled water. From this preparation, $2 \mathrm{ml}$ was given orally to the bulls of GH group consecutively on four days (30X, 200X, 1M \& 10M on 4,3,2 \&1 day, respectively) before FMD vaccination.

\section{Recording of observations}

Semen samples were collected by artificial vagina technique twice in a week from each bull. The fresh ejaculates were subjected to evaluation for volume, sperm concentration and initial sperm motility and as per standard procedures. The concentration of spermatozoa was measured with Accucell photometer (IMV Technologies, France). Sperm motion characteristics viz. progressive motility, average path velocity (VAP), straight line velocity (VSL), amplitude of lateral head displacement (ALH) and linearity (LIN) were assessed with ComputerAssisted Sperm Analyzer (CASA, Hamilton Thorn-IVOS 12). The observations were recorded for six weeks post vaccination. The rectal temperature of experimental animals was recorded with a mercury thermometer with sensitivity to $0.2^{\circ} \mathrm{F}$ inserted into the animal's rectum for 2 minutes in the morning and afternoon after vaccination up to $48 \mathrm{~h}$ post vaccination. Besides, the scrotum temperature on each bull was measured with infra-red thermometer [display: digital; model: Okaton Temp Testr IR; source of power: battery $(9 \mathrm{~V})$; unit: ${ }^{\circ} \mathrm{C},{ }^{\circ} \mathrm{F}$; range: $-18 \sim 260{ }^{\circ} \mathrm{C}$ (0-500 $\left.{ }^{\circ} \mathrm{F}\right)$; accuracy: $\pm 2 \%$ of reading; response time: $500 \mathrm{~m} \mathrm{Sec}$; distance to spot size (D:S): 6:1] at the same time during the same period of observations of rectal temperature.

\section{STATISTICAL ANALYSIS}

The experimental data were analyzed using analysis of variance, followed by a Duncan's post hoc test to determine significant differences in all the parameters recorded between groups using the SPSS/PC computer programme (Version 16.0, SPSS, Chicago, IL, USA). Differences with values of $\mathrm{P}<0.05$ were considered to be statistically significant.

\section{RESULTS AND DISCUSSION}

Table 1 depicts mean rectal temperature changes at different intervals in experimental bulls after FMD vaccination. All the bulls had normal body temperature up to $6 \mathrm{~h}$ 
Table 1: Mean \pm SE rectal temperature $\left({ }^{\circ} \mathrm{F}\right)$ of experimental bulls after vaccination

\begin{tabular}{llllll}
\hline \multirow{2}{*}{ Group } & \multicolumn{5}{c}{ Post FMD vaccination interval } \\
\cline { 2 - 5 } & $\mathbf{6} \mathbf{h}$ & $\mathbf{2 4} \mathbf{~ h}$ & $\mathbf{3 0} \mathbf{~ h}$ & $\mathbf{4 8} \mathbf{~ h}$ & $\mathbf{5 4} \mathbf{~ h}$ \\
\hline GC & $101.67 \pm 0.09$ & $100.30 \pm 0.19^{\mathrm{b}}$ & $101.67 \pm 0.18^{\mathrm{b}}$ & $100.40 \pm 0.26$ & $101.90 \pm 0.11$ \\
GV & $101.57 \pm 0.47$ & $101.93 \pm 0.46^{\mathrm{a}}$ & $102.53 \pm 0.12^{\mathrm{ac}}$ & $100.67 \pm 0.20$ & $101.83 \pm 0.32$ \\
GL & $101.80 \pm 0.19$ & $102.50 \pm 0.61^{\mathrm{a}}$ & $103.07 \pm 0.35^{\mathrm{a}}$ & $100.53 \pm 0.36$ & $101.37 \pm 0.29$ \\
GH & $101.87 \pm 0.35$ & $101.87 \pm 0.44^{\mathrm{a}}$ & $102.27 \pm 0.31^{\mathrm{bc}}$ & $100.97 \pm 0.38$ & $101.57 \pm 0.37$ \\
\hline
\end{tabular}

Means with different superscripts in a column differ significantly $(\mathrm{P}<0.05)$.

Table 2: Sperm motility and CASA sperm motion characteristics of experimental Frieswal bulls

\begin{tabular}{lllll}
\hline \multirow{2}{*}{ Parameters } & \multicolumn{3}{c}{ Groups } \\
\cline { 2 - 5 } & GC & GV & GL & GH \\
\hline Initial subjective motility $(\%)$ & $68.33 \pm 1.67^{\mathrm{b}}$ & $67.50 \pm 2.17^{\mathrm{ab}}$ & $62.50 \pm 2.17^{\mathrm{a}}$ & $71.00 \pm 1.79^{\mathrm{b}}$ \\
CASA progressive motility $(\%)$ & $61.25 \pm 2.58^{\mathrm{a}}$ & $53.75 \pm 2.39^{\mathrm{b}}$ & $60.75 \pm 2.28^{\mathrm{a}}$ & $65.10 \pm 2.42^{\mathrm{a}}$ \\
VAP $(\mu \mathrm{m} / \mathrm{sec})$ & $132.67 \pm 4.71^{\mathrm{a}}$ & $125.10 \pm 3.41^{\mathrm{ab}}$ & $118.74 \pm 4.08^{\mathrm{b}}$ & $121.49 \pm 5.39^{\mathrm{ab}}$ \\
VSL $(\mu \mathrm{m} / \mathrm{sec})$ & $114.63 \pm 4.94^{\mathrm{a}}$ & $103.53 \pm 3.66^{\mathrm{ab}}$ & $98.2 \pm 3.72^{\mathrm{b}}$ & $104.77 \pm 4.41^{\mathrm{ab}}$ \\
ALH $(\mu \mathrm{m})$ & $7.55 \pm 0.24^{\mathrm{ab}}$ & $7.94 \pm 0.24^{\mathrm{a}}$ & $7.63 \pm 0.29^{\mathrm{ab}}$ & $7.03 \pm 0.33^{\mathrm{b}}$ \\
LIN $(\%)$ & $54.50 \pm 1.37^{\mathrm{b}}$ & $49.75 \pm 1.23^{\mathrm{a}}$ & $50.33 \pm 1.39^{\mathrm{a}}$ & $54.70 \pm 1.45^{\mathrm{b}}$ \\
\hline
\end{tabular}

Means with different superscripts in a row differ significantly $(\mathrm{P}<0.05)$.

post vaccination on same day. Similar rectal temperature range in Frieswal bulls was reported by Sirohi et al. (2017) during the same season of experiment. However, average rectal temperature in vaccinated bulls increased significantly $(\mathrm{p}<0.05)$ than in non-vaccinated bulls after $24 \mathrm{~h}$ of FMD vaccination. In GH, it was similar to GC after $36 \mathrm{~h}$, however, became normal in all groups after $48 \mathrm{~h}$ of vaccination. The results are in agreement to the findings of Venkatareddy et al. (1991) who reported higher body temperature of bulls after FMD vaccination, which might be due to anaphylactic reactions after vaccination. Similarly, Ferreira et al. (2016) observed that rectal temperature in FMD vaccinated cows was significantly $(<0.01)$ higher than in non-vaccinated cows $(103.28 \mathrm{vs}$ $102.56^{\circ} \mathrm{F}$ ) at $24 \mathrm{~h}$ post vaccination. FMD vaccination had no effect on change of scrotal surface temperature in these bulls during the observations recorded on rectal temperature. Scrotal surface temperature ranged from $31.96 \pm 0.18$ (morning) to $34.51 \pm 0.16{ }^{\circ} \mathrm{C}$ (afternoon) in experimental bulls.

During first three weeks of post FMD vaccination, no significant difference was observed for initial subjective sperm motility among different groups, however, during next part of the experiment, $\mathrm{GC}$ and $\mathrm{GH}$ had similar and significantly higher sperm motility than $\mathrm{GV}$ and
GL. Though the CASA sperm motion characteristics were similar between groups during first week of FMD vaccination, significant differences were observed for these parameters during third and fourth week post vaccination (Table 2). Average VAP which is a useful semen motility characteristic having clinical relevance in the prediction of fertility (Nagy et al., 2015) and VSL values were higher $(p<0.05)$ in GC than in treatment groups. Among vaccinated groups, $\mathrm{GH}$ bulls had higher $(\mathrm{p}<0.05)$ initial sperm subjective and CASA progressive motility than in GV bulls. FMD vaccinated bulls without any treatment had least $(p<0.05)$ CASA progressive motility. The high sperm motility in GH bulls might be due to effective stimulated cell-mediated immune system and decrease pro-inflammatory cytokines by $T$. occidentalis (Sunila et al., 2011).

The significant decline in sperm motility was observed after FMD (Sirohi et al., 2016) and IBR, HS and BQ (Mathur et al., 2003) vaccination in Frieswal bulls. Similar to the present findings, Venkatareddy et al. (1991) reported that decrease in sperm motility might be due to the anaphylactic stress effect of vaccination. The effect of increased temperature on epididymal spermatozoa could give rise to sperm abnormalities (Venkataswami and Rao, 1970). However, in the present study, no significant rise of scrotal 
temperature indicated that testicular temperature might have been regulated well due to effective thermoregulatory process. For ALH values, no specific trend was observed between the experimental groups. Average linearity values in $\mathrm{GH}$ were equal to that of GC, however, least values were recorded in GV. After six weeks of vaccination, no significant difference was observed for CASA parameters between groups except VSL values which continued to be significantly higher $(\mathrm{p}<0.05)$ in GC than in GL but it was similar in GV and GH. The observations on VSL and VAP of the present study are in agreement to the findings of Sundararaman (2012) who reported similar velocities in bull semen (71.5 and $90.5 \mu \mathrm{m} / \mathrm{s}$ for VSL and VAP).

The total sperm abnormalities (head, mid-piece and tail) were within the prescribed limit $(<20 \%)$ of semen preservation. These abnormalities were significantly lower in non-vaccinated than in vaccinated bulls. In agreement to the present study, Sirohi et al. (2016) observed higher $(25.32 \%)$ total sperm abnormalities during the first month post FMD vaccination than before vaccination (14.50\%). In agreement to the above findings, Singh et al. (2003) observed that the FMD vaccination produced adverse effects on the semen quality of buffalo bulls up to one month after vaccination. It may be concluded that the homoeopathy drug Thuja was able to prevent deterioration in sperm kinetic parameters subsequent to FMD vaccination in crossbred bulls. Moreover, Levamisole was found to be ineffective in the improvement of semen quality in FMD vaccinated bulls.

\section{ACKNOWLEDGEMENTS}

The authors are thankful to the Director, ICAR-Central Institute for Research on Cattle and Director, Frieswal Project for providing necessary facilities for conducting the experiment.

\section{REFERENCES}

Abath, F.G.C. 1988. The use of non-specific immunopotentiators in Trypanossoma cruzi infection. Trans. R. Soc. Trop. Med. Hyg., 82: 73-76.

Duarte, K.M.R., Melo, A.J.F. de., Gomes, L.H., Farias, J.F., Poncio, V. and Alvarez, R.H. 2019. Levamisole-Phosphate Used In Dairy Cattle on Pre- Parturient and Reproductive Performance during Post-Parturient Period. J. Agric. Vet. Sci., 12: 81-86.

Ferreira, L.C., Cook, R.F., Marques, R.S., Fernandes, S.J.,
Fernandes, C.E., Stelato, R., Franco, G.L. and Memos, R.A. 2016. Effects of vaccination against foot-and-mouth disease virus on reproductive performance of beef cows. J. Anim. Sci., 94: 401-405.

Mathur, A.K., Tyagi, S.K., Mandal, D.K. and Singh, S.P. 2003. Effect of multiple vaccinations on the semen quality of Frieswal bulls. Indian J. Anim. Sci., 73: 864-866.

Montenegro, S.M.L. 1992. Efeitos de imunopotencidores não específicos na infecção experimental pelo Schistosoma mansoni. I. Levamisole. Rev. Inst. Med. Trop. Sao Paulo., 33: 69-73.

Murugavel, K., Veerapandian, C. and Subramanian, A. 1997. Effect of black quarter vaccination on semen quality in Murrah bulls. Indian J. Anim. Sci., 67: 597-598.

Nagy, A., Polichronopoulos, T., Gaspardy, A., Solti, L. and Cseh, S. 2015. Correlation between bull fertility and sperm cell velocity parameters generated by computer-assisted semen analysis. Acta. Vet. Hung., 63: 370-381.

Naser, B., Bodinet, C., Tegtmeier, M. and Lindequist, U. 2005. Thuja occidentalis (Arbor vitae): A Review of its Pharmaceutical, Pharmacological and Clinical Properties. Evid. Based Complement Alternat. Med., 2: 69-78.

Perumal, P., Khate, K. and Rajkhowa, C. 2013. Effect of foot and mouth disease vaccination on seminal and biochemical profiles of Mithun (Bos frontalis) semen. Asian Pac. J. Reprod., 2: 178-184.

Singh, R., Verma, H.K. and Kumar, S., 2003. Effect of the foot and mouth disease vaccination on the semen quality of buffalo bulls. Indian J. Anim. Sci., 73: 1319-1323.

Sirohi, A.S., Chand, N., Tyagi, S., Srivastava, N., Sharma, A. and Hemlata. 2016. Effect of FMD vaccination on various semen quality parameters in Frieswal crossbred bull. Indian J. Anim. Sci. 86: 904-906.

Sirohi, A.S., Chand, N., Tyagi, S., Kumar, S., Sharma, A. and Singh, C.P. 2017. Effect of shed designing on physiological responses and semen quality of crossbred bulls during various seasons. J. Anim. Res. 7: 891-895.

Sunila, E.S., Hamsa, T.P and Kuttan, G. 2011. Effect of Thuja occidentalis and its polysaccharide on cell-mediated immune responses and cytokine levels of metastatic tumor-bearing animals. Pharm. Biol., 49: 1065-1073.

Venkatareddy, J., Venkatamunichetty, A., Ramachandran, S.V. and Sreeraman. 1991. Effect of foot and mouth disease vaccination on semen quality. Indian J. Anim. Reprod., 12: 13-14.

Venkataswami, V. and Rao, V.J. 1970. Preliminary report on the effect of foot and mouth disease vaccination on semen quality of crossbred bulls. Indian Vet. J., 47: 23-29.

Waites, G.M.H. and Setchell, B.P. 1990. Physiology of the mammalian testis. Marshall's Physiology of reproduction. $4^{\text {th }}$ edn., (Ed) Lamming, G.E. Churchill Livingstone, Edinburgh, UK, pp. 1-105. 